\title{
CAUSAL MAPPING TO EXPLORE EMERGENCE OF CONSTRUCTION DISPUTES
}

\author{
Cenk TANRIVERDI ${ }^{(0)}$, Guzide ATASOY ${ }^{*}$, Irem DIKMEN ${ }^{\circledR}$, M. Talat BIRGONUL (D) \\ Department of Civil Engineering, Middle East Technical University, Ankara, Turkey
}

Received 19 February 2021; accepted 15 April 2021

\begin{abstract}
Disputes, frequently encountered in construction projects, can substantially affect project success, necessitating a clear understanding of how and why disputes occur. Previous studies on disputes mostly yielded exhaustive lists or hierarchies of possible causes of disputes, which can hardly be used to understand how these causes come together to form a dispute. To address this gap, this study provides an alternative approach to understand the underlying causes of disputes, and their relationship within a specific context, using causal map analysis. This study is conducted using causal mapping approach to understand dispute emergence patterns in practice. Initially, a causal map of construction disputes is developed based on literature. The map is altered and verified through an expert workshop, considering projects contracted through FIDIC Yellow Book. The causal representation of the dispute emergence patterns highlights the importance of pre-construction studies, people factor, and contract terms. It is revealed that significant causes are either result of a chain of preceding factors or are triggers for further ones. This finding reinforces that the occurrence of disputes does not only depend on individual causes; rather, these causes combine with a series of other factors for a dispute to occur.
\end{abstract}

Keywords: construction industry, dispute, causal map, contract management, FIDIC, workshop.

\section{Introduction}

Construction projects involve different work disciplines and various stakeholders having different interests and perspectives, aiming to maximize their own benefits. When this system of highly interacting stakeholders is combined with the usually complex contractual arrangements employed in the construction industry, conflicts between the parties become inevitable (Rhys Jones, 1994; Yiu \& Cheung, 2006). In fact, with its reputation for being highly litigious, the construction industry, quite paradoxically, has been a leader both in the occurrence of disputes and dispute resolution systems it employs (Michel, 1998; Keil, 1999).

When contractually filed and communicated, conflicts turn into claims, which can be described as "a request for compensation for damages incurred by any party to the contract" (Semple et al., 1994). While some of the claims are amicably resolved without causing significant problems, some may have further implications, which result in a substantially prolonged process for resolution if a resolution or an agreement is eventually reached. Within this context, disputes can be associated with specific judicial issues that require resolution and are one of the main causes preventing successful completion of a construction project in terms of cost, time, and quality (Fenn et al., 1997). Considerably high costs and losses associated with disputes force the construction industry to shift its focus from resolving disputes to avoiding those in the first place with the idea that "prevention is better than cure" (Fisher, 1988). In this sense, dispute prevention (avoidance) can be an utterly promising way of eliminating associated value and revenue losses. It can be such as promising way as it avoids the costs associated with dispute resolution, the hostility between parties, and further damages incurred despite the resolution. Avoiding disputes, however, requires a thorough and clear grasp of the events and circumstances giving rise to disputes, which in turn should enable contract parties to identify and focus on the issues/ aspects and their relationships. The literature is limited in demonstrating the causal relations of construction disputes for different project contexts. Cognitive maps provide researchers and practitioners with a holistic view of the project that can be used to improve understanding of how disputes occur (Ackermann \& Alexander, 2016).

${ }^{*}$ Corresponding author. E-mail: guzide@metu.edu.tr

Copyright $\odot 2021$ The Author(s). Published by Vilnius Gediminas Technical University

This is an Open Access article distributed under the terms of the Creative Commons Attribution License (http://creativecommons.org/licenses/by/4.0/), which permits unrestricted use, distribution, and reproduction in any medium, provided the original author and source are credited. 
The objective of this study is to explore the potential use of the causal mapping approach to understand the causes of disputes and their interactions with each other. It is believed that the determination of alternative dispute emergence patterns eventually would help construction professionals to take proactive measures to avoid disputes. To demonstrate the utilization of causal mapping for exploring disputes in construction projects, a causal map was developed with the contribution of domain experts. The causal map focuses on Design and Build (DB) projects contracted under Federation Internationale des Ingenieurs-Conseils (FIDIC, 1999) Yellow Book. With a long track of familiarity and precedence, FIDIC is the most widely utilized international contract, commonly used by international organizations and governments (Besaiso et al., 2018). There are differences in the format and content of FIDIC Books (e.g., silver, yellow). Transferring the expert knowledge requires focusing on a particular case because the strength of causal maps lies in their power to reveal the understanding of a particular situation. Hence, this study's scope is bounded to a specific case, DB projects contracted with FIDIC Yellow Book.

\section{Point of departure}

\subsection{Causes of construction disputes}

Various studies identified and enumerated the causes of disputes with varying perspectives. Bristow and Vasilopoulos (1995) and Sykes (1996) set forth a broad context and note unrealistic expectations, lack of team spirit, and misunderstandings as three main causes of disputes. Particularly emphasizing variations, Sheridan (2003) lists the valuation of variations and valuation of final account among the most significant factors. According to Hewitt (1991), in addition to the change of scope, change in conditions, delay, disruption, acceleration, and termination are major events giving rise to disputes. Perceiving "conflicting factors" as causes of disputes and underlining people factor, Acharya et al. (2006) identifies five dispute areas; owner, consultant, contractor, third parties, and other project specific matters. Also, adopting people's perspective, Ashworth (2005) categorizes causes of disputes as general, employer, consultants, contractors, subcontractors, and suppliers.

There is extensive research on the causes and occurrences of construction disputes that mainly resulted from possibly several underlying causes. However, they lack a clear understanding of how those causes affect or trigger each other to form a dispute that prevents practical use of these findings. Regarding construction disputes, the literature is saturated with works identifying various causes and returning exhaustive lists of factors contributing to the occurrence of disputes (e.g., Jaffar et al., 2011; El-Sayegh et al., 2020; Naji et al., 2020; Viswanathan et al., 2020). Several researchers worked on developing a clear terminology and taxonomy to investigate the emergence of disputes and to identify "pathogenic influences" for dispute causation (e.g., Ilter, 2012; Love et al., 2010). Vari- ous researchers attempted to explore this phenomenon by adopting different methods such as process models (Mitropoulos \& Howell, 2001), fuzzy fault trees (Cheung \& Yiu, 2006; Cheung \& Pang, 2013), analytic hierarchy process (Acharya et al., 2006; Creed \& Joon, 2009) subject matter and diagnostic approach (Cheung, 2014), analytic induction (Love et al., 2011), logistic regression (Diekmann \& Girard, 1995), structural equation modelling (Molenaar et al., 2000; Naji et al., 2020), root cause analysis (Parchami Jalal et al., 2019; Arif \& Saeed, 2021), cognitive mapping and system dynamic simulation modelling (Ackermann et al., 1997) and interpretive structuring modelling (ISM) (Viswanathan et al., 2020). Anatomy model by Cheung and Pang (2013) includes five levels of dispute hierarchy and systematic hierarchy model by Viswanathan et al. (2020) is constructed through ISM. Such models are basically hierarchical structures based on the data of previous projects. Arif and Saeed (2021) explores the bottlenecks in the arbitration process. Fishbone diagram by Parchami Jalal et al. (2019) shows the root causes of most frequent claims in the Iranian construction industry procured with Design-Bid-Build contracts. However, fishbone diagrams are limited in reflecting the relative importance and interrelationship between multiple factors. Love et al. (2011) pinpoints the abundant number of research studies on the identification of causes of disputes and states the lack of missing context due to the use of questionnaires and previous case documents. Among the limited studies of network-based models in this area, Ackermann et al. (1997) includes qualitative (cognitive mapping) and quantitative methods (system dynamics) together. Finding a pattern/ network of factors influencing each other, such a model may be used to serve as a tool to defend a disruption and delay claim. Despite proving the applicability and practical use of causal mapping to trace the emergence of claims, in the study by Ackermann et al. (1997), causal mapping was used as a post-mortem tool to defend a given claim case. This study identifies the need to make sense of the dependencies and patterns of dispute causes. Differentiating from the previous studies, the central idea of this study is to use the causal mapping approach to explore why and how disputes emerge in projects and identify patterns.

\subsection{Causal mapping approach}

Cognitive mapping is a technique enabling revelation and actively shaping the mental models or belief systems (cognitive models, mind maps) utilized by people to perceive, contextualize, simplify, and make sense of problems that are otherwise considered to be complex (Ackermann \& Eden, 2010). Causal mapping falls within an extensive body of techniques referred to as cognitive mapping as a whole (Huff, 1990; Axelrod, 2015; Tolman, 1948). Numerous methods are proposed for causal mapping (Narayanan \& Armstrong, 2005; Eden et al., 1998; Huff, 1990). Among them, this study follows the approach developed by Eden 
and colleagues (Bryson et al., 2014; Ackermann \& Eden, 2011; Eden, 1992). Eden's approach is an interactive decision-support tool enabling capturing and analysis of complex problems (Georgiou, 2010). This theory forms a comprehensive foundation for understanding how individuals make sense of their experiences. According to this theory, people actively and constantly anticipate events and issues by hypothesizing what might occur in the future based on experience and consequently testing these hypotheses (Kelly, 1955). New constructs are added to the existing set of constructs as a result of this constant process. Hence, it can be postulated that people make sense of their world by comparing and contrasting facts, observations, events, and similar to find out their meaning and to help route what is forthcoming (Ackermann, \& Eden, 2010).

From a practical point of view, causal maps are basically directed graphs, in which impressions of situations are shown as statements (nodes), and these statements are connected through causal links (Eden, 1992). Links between the nodes are represented with arrows indicating a causal relationship between these concepts. Causal maps are considered to be either idiographic or nomothetic, depending on the purpose. Idiographic causal mapping aims at developing a sound apprehension of a situation (Cossette \& Audet, 1992). Thus, it aims at reaching a thorough understanding of a phenomenon. The nomothetic method is engaged with ascertaining themes or patterns in a map that can be statistically generalized (Hodgkinson \& Clarkson, 2005). Since this study aims at providing a comprehensive understanding of construction disputes, the idiographic approach is adopted as part of the research methodology. The idiographic approach involves a semistructured data elicitation technique to explore details of an issue where a relatively small sample size is considered (Bryson et al., 2004). In this sense, researchers following this approach can investigate details regarding a given situation or phenomenon at length, enabling the uncovering of unique understandings.

\section{Research design and methodology}

Creating a causal map from scratch and analysing the map to facilitate a broader understanding of disputes in the construction industry form the backbone of this study. For this purpose, first, a broad set of causes of disputes mentioned in the literature was identified by an extensive literature survey. Then, the knowledge and experience of professionals were utilized to form the causal map for a specific case, which is DB projects contracted with FIDIC Yellow Book. In the common approach, the concepts forming the causal map are uncovered during the workshop. At this juncture, however, the lack of available expert time compared to the highly time-consuming mapping process posed a significant challenge. To overcome this challenge, unlike the common approach, first, an initial map was constructed to illustrate findings from the literature. The initial map was revised as per the views and comments of experts to reach a final map that can be used for analysis. Based on this research design, Figure 1 shows the series of steps followed in this study.

During the search for a computer tool that can be used for purposes of causal mapping, two software tools (Decision Explorer and Dialogue Mapping) are discovered to be readily available. In this study, Decision Explorer (DE) is employed, as it has a relatively easy-to-use interface, numerous map analysis options, and a recent track record for uses in project management (Edkins et al., 2007; Ackermann et al., 2014). DE is stated to be the most advanced computer support tool for cognitive mapping (Goodier \& Soetanto, 2013). Analysis tools that can be utilized to study the map in-depth and unveil latent dynamics of the issue being investigated are also readily available within DE software. The analysis tools on the content and structure of the map within DE are rooted in the analytical techniques of Graph Theory (Eden \& Ackermann, 2004; Santos et al., 2019). Among these, domain analysis, centrality analysis, and loop analysis were considered to suffice for the purpose of the study, along with commands: Explanations and Consequences.

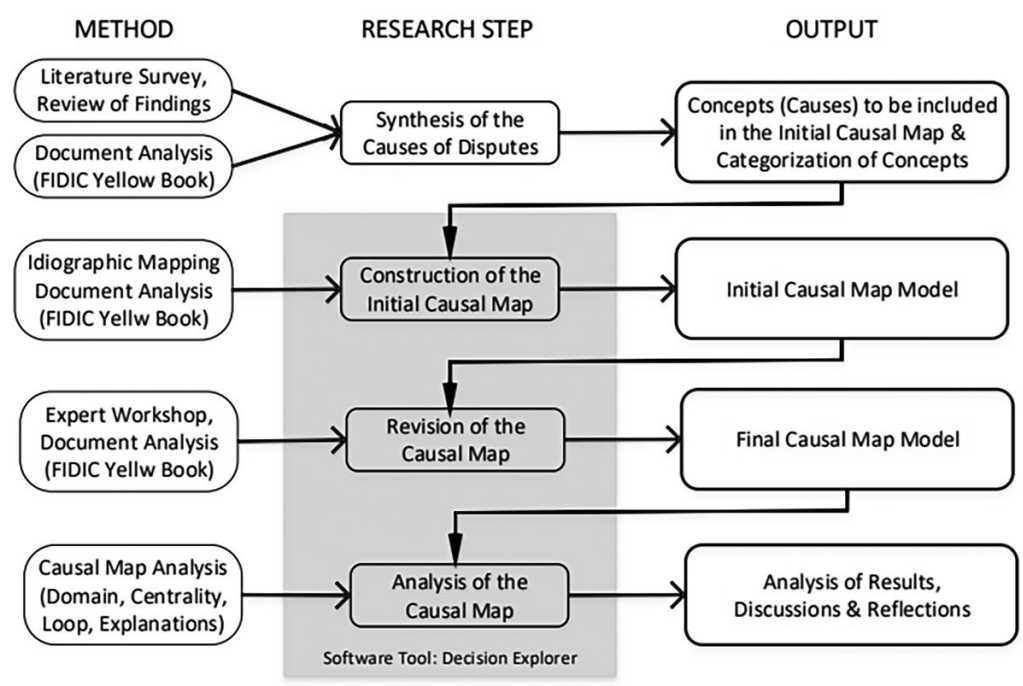

Figure 1. Research steps 


\subsection{Identification of causes of construction disputes}

Identifying the causes of construction disputes formed the first step towards building an initial map. To ensure all causes, which are pertinent to the issue, are covered to the extent possible, a thorough literature review on the causes of construction disputes was conducted. Table 1, Table 2, and Table 3 present the process, project, and people related dispute causes, respectively. Based on the literature findings, an initial map was constructed to collect expert opinions.

\subsubsection{Construction of the initial causal map}

Once the factors contributing to the occurrence of disputes were identified, these were carefully reviewed to detect any overlapping meaning and to avoid any duplication. During this review, factors that were either not applicable or irrelevant with respect to risk allocation and responsibilities of parties as defined in FIDIC Yellow Book were excluded. Also, the expressions for concepts covering a broad concept instead of a specific cause were refined to ensure causal relations between the concepts can be clearly understood. Once the concepts were identified and refined, causal links between these concepts were created using DE software. To establish accurate and reliable causal relations between the concepts, common industrial practice, correlative relations of the concepts, and responsibilities of parties designated by FIDIC Yellow Book were considered. Before explaining how this causal map was finalized as a result of the workshop, the fundamentals of causal mapping are depicted in the next section.

\subsubsection{Development of the final causal map: The expert workshop}

Playing the key role of reflecting an extensive body of information and experience into a study, knowledge elicitation is a core aspect of constructing a reliable causal map.

Table 1. Causes of construction disputes (Process)

\begin{tabular}{|c|c|c|}
\hline & Dispute Cause & Source/References \\
\hline \multirow{7}{*}{ 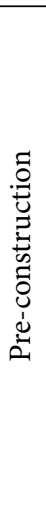 } & Unrealistic expectations of employer & $\begin{array}{l}\text { Bristow and Vasilopoulos (1995), Sykes (1996), Yates (1999), Molenaar et al. } \\
\text { (2000), Chan and Suen (2005), Love et al. (2010), Sabri et al. (2019), Viswanathan } \\
\text { et al. (2020), Naji et al. (2020) }\end{array}$ \\
\hline & $\begin{array}{l}\text { Lack of involvement of inputs from all } \\
\text { groups }\end{array}$ & Molenaar et al. (2000), Love et al. (2010) \\
\hline & Insufficient financial planning & Molenaar et al. (2000), Ashworth (2005), El-Sayegh et al. (2020) \\
\hline & Project uncertainty & $\begin{array}{l}\text { Mitropoulos and Howell (2001), Cheung and Yiu (2006), Love et al. (2010), } \\
\text { Cheung and Pang (2014) }\end{array}$ \\
\hline & Bid development/ estimating errors & Yates (1999), Ashworth (2005), Cheung and Yiu (2006), Sabri et al. (2019) \\
\hline & Errors in concept design/ planning & $\begin{array}{l}\text { Yates (1999), Ashworth (2005), Acharya et al. (2006), Waldron (2006), Sabri et al. } \\
\text { (2019), El-Sayegh et al. (2020) }\end{array}$ \\
\hline & Unfamiliarity with local conditions & Chan and Suen (2005) \\
\hline \multirow{10}{*}{ 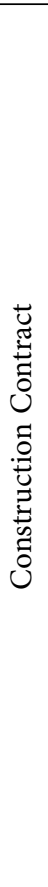 } & Unclear scope definition & $\begin{array}{l}\text { Ashworth (2005), Chan and Suen (2005), Acharya et al. (2006), Ilter (2012), } \\
\text { El-Sayegh et al. (2020) }\end{array}$ \\
\hline & Ambiguities in contract documents & $\begin{array}{l}\text { Spittler and Jentzen (1992), Bristow and Vasilopoulos (1995), Kumaraswamy } \\
\text { (1997), Yates (1999), Mitropoulos and Howell (2001), Ashworth (2005), Chan and } \\
\text { Suen (2005), Cheung and Yiu (2006), Ilter (2012), Cheung and Pang (2014), Sabri } \\
\text { et al. (2019), El-Sayegh et al. (2020), Viswanathan et al. (2020) }\end{array}$ \\
\hline & $\begin{array}{l}\text { Double meaning of specifications, } \\
\text { different/ misinterpretations }\end{array}$ & $\begin{array}{l}\text { Adriaanse (2005), Chan and Suen (2005), Acharya et al. (2006), Waldron (2006), } \\
\text { Love et al. (2010), Sabri et al. (2019), El-Sayegh et al. (2020) }\end{array}$ \\
\hline & Change of scope & $\begin{array}{l}\text { Hewitt (1991), Semple et al. (1994), Ashworth (2005), Cheung and Yiu (2006), } \\
\text { Waldron (2006), Love et al. (2010), Sabri et al. (2019), Naji et al. (2020), } \\
\text { Viswanathan et al. (2020) }\end{array}$ \\
\hline & $\begin{array}{l}\text { Differences in evaluation of changes } \\
\text { (variations) }\end{array}$ & $\begin{array}{l}\text { Hewitt (1991), Sheridan (2003), Acharya et al. (2006), Cheung and Yiu (2006), } \\
\text { Love et al. (2010) }\end{array}$ \\
\hline & Lack of formal dispute resolution process & Sabri et al. (2019), El-Sayegh et al. (2020) \\
\hline & Unrealistic/ non-practical obligations & Acharya et al. (2006), Cheung and Yiu (2006) \\
\hline & Unbalanced risk allocation & $\begin{array}{l}\text { Yates (1999), Molenaar et al. (2000), Chan and Suen (2005), Acharya et al. (2006), } \\
\text { Love et al. (2010), Cheung and Pang (2014) }\end{array}$ \\
\hline & $\begin{array}{l}\text { Different interpretation of escalation/ } \\
\text { de-escalation }\end{array}$ & Acharya et al. (2006), Love et al. (2010) \\
\hline & Variations/change orders & $\begin{array}{l}\text { Kumaraswamy (1997), Yates (1999), Adriaanse (2005), Ashworth (2005), Acharya } \\
\text { et al. (2006), Chan and Suen (2005), Ilter (2012), El-Sayegh et al. (2020), Naji et al } \\
(2020)\end{array}$ \\
\hline
\end{tabular}


Table 2. Causes of construction disputes (Project)

\begin{tabular}{|c|c|c|}
\hline & Dispute Cause & Source/References \\
\hline \multirow{8}{*}{ 茎 } & $\begin{array}{l}\text { Variations due to external events/ } \\
\text { codes/regulations }\end{array}$ & $\begin{array}{l}\text { Kumaraswamy (1997), Yates (1999), Chan and Suen (2005), Acharya et al. (2006), } \\
\text { El-Sayegh et al. (2020) }\end{array}$ \\
\hline & $\begin{array}{l}\text { Unforeseen ground conditions/ } \\
\text { inadequate site investigations }\end{array}$ & Kumaraswamy (1997), Yates (1999), El-Sayegh et al. (2020) \\
\hline & Inferences with utility lines & Kumaraswamy (1997) \\
\hline & Exceptional inclement weather & $\begin{array}{l}\text { Semple et al. (1994), Kumaraswamy (1997), Yates (1999), Acharya et al. (2006), El- } \\
\text { Sayegh et al. (2020) }\end{array}$ \\
\hline & $\begin{array}{l}\text { Delayed site possessions/restricted } \\
\text { access }\end{array}$ & $\begin{array}{l}\text { Hewitt (1991), Semple et al. (1994), Kumaraswamy (1997), Yates (1999), Acharya et al. } \\
\text { (2006), Adriaanse (2005), Cheung and Yiu (2006), Waldron (2006), Love et al. (2010), } \\
\text { Naji et al. (2020) }\end{array}$ \\
\hline & $\begin{array}{l}\text { Public interruptions/municipality } \\
\text { approvals }\end{array}$ & Acharya et al. (2006), El-Sayegh et al. (2020) \\
\hline & Environmental issues & Acharya et al. (2006), El-Sayegh et al. (2020) \\
\hline & Site limitations / differing conditions & Acharya ey al. (2006), Waldron (2006), Love et al. (2010), El-Sayegh et al. (2020) \\
\hline \multirow{9}{*}{ 胥 } & Design errors by contractor & Watts and Scrivener (1995) \\
\hline & $\begin{array}{l}\text { Incomplete or substandard } \\
\text { information }\end{array}$ & $\begin{array}{l}\text { Yates (1999), Molenaar et al. (2000), Chan and Suen (2005), Waldron (2006), Ilter } \\
\text { (2012), El-Sayegh et al. (2020) }\end{array}$ \\
\hline & $\begin{array}{l}\text { Delayed design information or } \\
\text { drawings }\end{array}$ & $\begin{array}{l}\text { Hewitt (1991), Kumaraswamy (1997), Yates (1999), Adriaanse (2005), Acharya et al. } \\
\text { (2006) }\end{array}$ \\
\hline & $\begin{array}{l}\text { Nonexistence of previous similar } \\
\text { projects (Pioneer project) }\end{array}$ & Molenaar et al. (2000) \\
\hline & Design and construction complexity & Molenaar et al. (2000) \\
\hline & Size (scale of project) & Molenaar et al. (2000) \\
\hline & Material testing technique & Acharya et al. (2006) \\
\hline & $\begin{array}{l}\text { Low-quality/ defective works by } \\
\text { contractor }\end{array}$ & $\begin{array}{l}\text { Adriaanse (2005), Ashworth (2005), Acharya et al. (2006), Chan and Suen (2005), } \\
\text { Love et al. (2010), Sabri et al. (2019) }\end{array}$ \\
\hline & Difference in construction technique & Acharya et al. (2006) \\
\hline
\end{tabular}

Knowledge elicitation for causal maps can be carried out either through interviews (e.g., Bryson et al., 2004), documents (e.g., Eden \& Ackermann, 2004), or through workshops (e.g., Ackermann et al., 2014). In this respect, this study combines documents and workshops since the initial map that was built based on literature was then evaluated, revised, and enriched through an expert workshop. While designing the expert workshop, there were three primary considerations to ensure the effective use of limited available time, knowledge, and experience. These are the duration of the workshop, the background of experts, and the facilitation of the workshop.

The maximum duration an expert could allocate for the workshop was around half-a-day (4 hours). During this time, it would be practically not possible to reflect all expert views and comments on the initial causal map due to relatively high number of (66) concepts. With this respect, instead of carrying out changes on the map during the workshop, the entire workshop was recorded via a voice recorder. Transcript of this record was then used to carry out changes on the initial map as per experiences, views, and comments shared by experts during the workshop.

Any or all of the parties involved in a construction project may either initiate or play a role in conflicts resulting in claims and disputes. This fact makes it essential to include perspectives of all stakeholders for rigour in understanding the occurrence of disputes. For this reason, in the case of FIDIC Yellow Book, priority was given to the selection of experts. Experts with backgrounds that can collectively represent perspectives of the various parties, including engineers, employers, contractors, and other possible third parties were selected. Relevance with the construction disputes and experience working with FIDIC forms of contract were other significant concerns regarding expert backgrounds. Table 4 presents a summary of the experts' backgrounds. All experts, whose experience range from 15 to 40 years, have frequently worked in projects using FIDIC contracts. The expert with the least FIDIC and dispute experience was involved in at least three projects with major dispute cases, while all of the experts were involved in various DB projects.

In light of the considerations explained above, a halfday workshop with the participation of five experts was designed to construct the causal map. The first session of the workshop began with a presentation of the aim, methodology, and scope of the study and causal mapping technique. Experts were then encouraged to brainstorm on the occurrence of construction disputes. Planned as a semistructured discussion, the aim of this session was to particularly allow experts to freely discuss the phenomenon based on their previous experience. During the discussion, 
Table 3. Causes of construction disputes (People)

\begin{tabular}{|c|c|c|}
\hline & Dispute Cause & Source/References \\
\hline \multirow{9}{*}{ 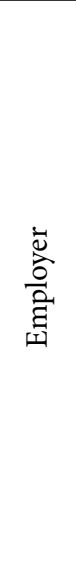 } & Employer's incapable management & Molenaar et al. (2000), Chan and Suen (2005), Acharya et al. (2006), Ilter (2012) \\
\hline & $\begin{array}{l}\text { Employer's lack of experience with } \\
\text { project and contract type }\end{array}$ & Love et al. (2010), Molenaar et al. (2000), Viswanathan et al. (2020) \\
\hline & Confusing requirements of employer & Acharya et al. (2006) \\
\hline & Acceleration of works by employer & Hewitt (1991), Semple et al. (1994), Acharya et al. (2006), Naji et al. (2020) \\
\hline & Disruption of progress by employer & Hewitt (1991), Ashworth (2005), Cheung and Yiu (2006) \\
\hline & $\begin{array}{l}\text { Suspension of works by employer/ } \\
\text { stoppage }\end{array}$ & $\begin{array}{l}\text { Hewitt (1991), Watts and Scrivener (1995), Acharya et al. (2006), Viswanathan et al. } \\
(2020)\end{array}$ \\
\hline & $\begin{array}{l}\text { Postponement of part of the project } \\
\text { by employer }\end{array}$ & Yates (1999) \\
\hline & Delays in approvals by employer & $\begin{array}{l}\text { Hewitt (1991), Yates (1999), Adriaanse (2005), Acharya et al. (2006), Waldron } \\
\text { (2006), El-Sayegh et al. (2020), Viswanathan et al. (2020) }\end{array}$ \\
\hline & Delays in payment by employer & $\begin{array}{l}\text { Hewitt (1991), Watts and Scrivener (1995), Sheridan (2003), Adriaanse (2005), } \\
\text { Ashworth (2005), Chan and Suen (2005), Acharya et al. (2006), Cheung and Yiu } \\
\text { (2006), Love et al. (2010), Naji et al. (2020), Viswanathan et al. (2020) }\end{array}$ \\
\hline \multirow{4}{*}{ 总 } & Contractor's incapable management & $\begin{array}{l}\text { Yates (1999), Molenaar et al. (2000), Chan and Suen (2005), Acharya et al. (2006), } \\
\text { Love et al. (2010), El-Sayegh et al. (2020), Viswanathan et al. (2020) }\end{array}$ \\
\hline & $\begin{array}{l}\text { Contractor's lack of experience with } \\
\text { project and contract type }\end{array}$ & Molenaar et al. (2000) \\
\hline & $\begin{array}{l}\text { Contractor's inexperience/ } \\
\text { incompetence }\end{array}$ & $\begin{array}{l}\text { Molenaar et al. (2000), Acharya et al. (2006), Ilter (2012), Sabri et al. (2019), El- } \\
\text { Sayegh et al. (2020), Viswanathan et al. (2020) }\end{array}$ \\
\hline & $\begin{array}{l}\text { Contractor's familiarity with local } \\
\text { conditions }\end{array}$ & Ilter $(2012)$ \\
\hline \multirow{5}{*}{ 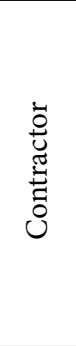 } & Contractor's negligence & Watts and Scrivener (1995), Acharya et al. (2006) \\
\hline & Delays by contractor & $\begin{array}{l}\text { Hewitt (1991), Watts and Scrivener (1995), Yates (1999), Adriaanse (2005), } \\
\text { Ashworth (2005), Acharya et al. (2006), Cheung and Yiu (2006), Sabri et al. (2019), } \\
\text { Naji et al. (2020), Viswanathan et al. (2020) }\end{array}$ \\
\hline & $\begin{array}{l}\text { Contractor's insufficient financial } \\
\text { resources }\end{array}$ & $\begin{array}{l}\text { Mitropoulos and Howell (2001), Acharya et al. (2006), Love et al. (2010), El-Sayegh } \\
\text { et al. (2020), Naji et al. (2020) }\end{array}$ \\
\hline & $\begin{array}{l}\text { Subcontractor inefficiency/ } \\
\text { inadequacy }\end{array}$ & Ashworth (2005), Acharya et al. (2006), Sabri et al. (2019) \\
\hline & Insufficient site management & Ashworth (2005), Acharya et al. (2006), El-Sayegh et al. (2020) \\
\hline \multirow{6}{*}{ 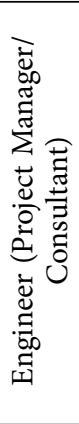 } & Engineer's incapable management & $\begin{array}{l}\text { Yates (1999), Chan and Suen (2005), Acharya et al. (2006), Love et al. (2010), } \\
\text { Viswanathan et al. (2020) }\end{array}$ \\
\hline & $\begin{array}{l}\text { Engineer's inexperience with project } \\
\text { type }\end{array}$ & Molenaar et al. (2000), Ashworth (2005) \\
\hline & Engineer's professional negligence & Watts and Scrivener (1995) \\
\hline & $\begin{array}{l}\text { Late/inadequate instructions/ } \\
\text { reviews/approvals/ responses by } \\
\text { engineer }\end{array}$ & $\begin{array}{l}\text { Ashworth (2005), Acharya et al. (2006), Cheung and Yiu (2006), El-Sayegh et al. } \\
(2020)\end{array}$ \\
\hline & Lack of coordination & Ashworth (2005) \\
\hline & $\begin{array}{l}\text { Inadequate description of engineer's } \\
\text { responsibilities }\end{array}$ & Molenaar et al. (2000), Ashworth (2005), Cheung and Yiu (2006) \\
\hline \multirow{8}{*}{ 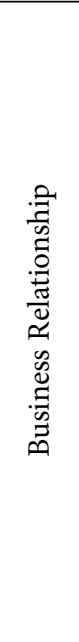 } & Lack of team building & $\begin{array}{l}\text { Bristow and Vasilopoulos (1995), Sykes (1996), Chan and Suen (2005), Cheung and } \\
\text { Yiu (2006) }\end{array}$ \\
\hline & Lack of history together & $\begin{array}{l}\text { Mitropoulos and Howell (2001), Ashworth (2005), Chan and Suen (2005), Cheung } \\
\text { and Yiu (2006) }\end{array}$ \\
\hline & Supremacy of engineer/ employer & Acharya et al. (2006) \\
\hline & $\begin{array}{l}\text { Lack of expectations of further } \\
\text { work/long-term relations }\end{array}$ & Mitropoulos and Howell (2001), Love et al. (2011) \\
\hline & Competitive/ adversarial attitude & $\begin{array}{l}\text { Spittler and Jentzen (1992), Chan and Suen (2005), Acharya et al. (2006), Cheung } \\
\text { and Yiu (2006), Ilter (2012), Cheung and Pang (2014), S. Mitkus and T. Mitkus } \\
\text { (2014), Sabri et al. (2019) }\end{array}$ \\
\hline & Opportunistic behaviour & $\begin{array}{l}\text { Molenaar et al. (2000), Mitropoulos and Howell (2001), Love et al. (2010), Cheung } \\
\text { and Pang (2014), S. Mitkus and T. Mitkus (2014), Viswanathan et al. (2020) }\end{array}$ \\
\hline & $\begin{array}{l}\text { Lack of communication between the } \\
\text { parties }\end{array}$ & $\begin{array}{l}\text { Bristow and Vasilopoulos (1995), Yates (1999), Ashworth (2005), Chan and Suen } \\
\text { (2005), Acharya et al. (2006), Ilter (2012), Cheung and Pang (2014), S. Mitkus and } \\
\text { T. Mitkus (2014), Sabri et al. (2019), El-Sayegh et al. (2020), Viswanathan et al. } \\
(2020)\end{array}$ \\
\hline & Excessive correspondence & Acharya et al. (2006) \\
\hline
\end{tabular}


Table 4. Summary of expert backgrounds

\begin{tabular}{|l|c|c|c|c|c|}
\hline \multicolumn{1}{|c|}{ Information/ Expert } & A & B & C & D & E \\
\hline Current role/ title & Academic & Academic & Contract Director & Consultant & General Coordinator \\
\hline Total years of experience & 20 & 40 & 15 & 40 & 30 \\
\hline $\begin{array}{l}\text { Level of experience with claims } \\
\text { and disputes }\end{array}$ & Very high & Very high & High & Moderate & Very High \\
\hline $\begin{array}{l}\text { Level of expertise with FIDIC } \\
\text { forms }\end{array}$ & High & High & High & Very High \\
\hline $\begin{array}{l}\text { Party represented at the } \\
\text { workshop }\end{array}$ & Consultant & Consultant & $\begin{array}{c}\text { Employer, Engineer, } \\
\text { Contractor }\end{array}$ & $\begin{array}{c}\text { Employer, } \\
\text { Consultant }\end{array}$ & $\begin{array}{l}\text { Contractor, } \\
\text { Consultant }\end{array}$ \\
\hline
\end{tabular}

questions such as "Why do you think disputes occur in construction", "Can you share a previous experience where you highly relate to the occurrence of disputes", and "Based on your previous experience, how do you think disputes mostly occur in construction business" were directed to the experts to sustain brainstorming and help experts express their views more clearly. The laddering method by Vygotsky (1980) was also utilized to investigate underlying causes (laddering down) and relations and outcomes (laddering $u p)$. For this reason, experts were asked the questions "In your opinion, what factors play a significant role in the occurrence of disputes", "In the experience you shared, what underlying issues played a key role", and "How do you relate these factors to result in a dispute".

In the second session, an initial causal map was presented to the experts both on a projection screen and as printouts. Presenting the map to the experts allowed them to reflect their thoughts and insight on the issue visually through a causal map. It also assisted them in identifying the concepts and their relations in mind as a result of their previous experience. In this regard, the main purpose of this session was to obtain expert views on the initial map for enhancement of the map. These views included an overall review of the concepts, identifying irrelevant concepts or statements, detecting any concept and links that must be added, and correcting links between the concepts that are not correct in the opinion of the experts. However, due to the relatively high number of concepts and the complexity arising from causal links, a complete review required significant time. Therefore, experts were asked to identify only highly significant errors or omissions at this stage. The initial map was revised by the authors after the workshop as per expert views shared during the workshop, and the resulting map was sent to the experts to obtain their opinion. This way, it was ensured that the experts had enough time with the map to check whether their views are adequately reflected. To enable easier tracking, links between the concepts were also transformed into a matrix form and sent to the experts to note the changes and corrections that should be made on the revised map.

\subsection{Analysis of the causal map}

Probing into the relations between map concepts (i.e., causes of disputes) provides an enhanced picture of the dynamics of the occurrence of disputes in construction.
With this aim, the final map achieved through the steps of the research method was analysed using the DE software. Domain, centrality, and loop analyses were combined with two main commands, Explanations and Consequences, to explore the outcomes and causes of significant concepts.

Domain analysis is a fundamental review of concepts, where each concept is treated separately, and the number of all the links immediately around each concept is calculated. At the end of the analysis, a list of all concepts showing their incoming, outgoing, and the total number of links is produced and printed on screen (Banxia, 2017). Domain analysis calculates the total number of concepts that are immediately linked to a concept by adding up the incoming and outgoing arrows to a concept. Concepts with the highest number of total links (link density) are considered as busy nodes, and they possibly indicate key concepts that require further investigation.

Unlike the domain analysis, centrality analysis takes into account not only the concepts immediately around a concept but also further relations that link through them. Due to this very fundamental difference, centrality analysis is capable of revealing a wider view of a concept within a map. The analysis employs a centrality scoring system in which the effect of the total number of links on the overall score reduces as the links move away from the concept. For instance, the total number of direct links to a concept (these linked concepts are regarded as second level concepts) is divided by 1 , whereas the number of links to and from the second level of concepts is divided into two and so on. Calculations do not take into account the direction of the arrows.

Loop analysis detects whether any loops were formed within the map. Also explained by Ackermann and Alexander (2016), loops are very important for analysing causal maps since they help determine whether a cyclic process is legitimate or not, vicious or virtuous. Reflecting these views into the occurrence of construction disputes, it is apparent that the interpretation of such loops can greatly help planning on preventive measures to avoid disputes.

The interactions between the causes were investigated by identifying causal link paths leading to or initiating from a given concept. To identify these paths were identified with explanations and consequences commands of DE. Explanations command follows the incoming links down to either branch points or to end concepts (tails), 
while Consequences traces the outgoing links to identify the nodes the selected concept is leading to (head). Both commands were run separately for the two most influential causes as per centrality analysis.

\section{Results}

\subsection{Development of the causal map}

As a result of the integration of literature findings and assessment of FIDIC Yellow Book, 66 causes (map concepts) were identified. These concepts were then grouped in line with Diekmann and Girard's (1995) approach, where sources of disputes are considered to be falling into either Process, Project, or People category. According to the same approach, Process was further divided into two as pre-construction studies and construction contracts; Project as external and internal, People as employer, contractor, engineer, and business relationship. This grouping of factors (shown in Table 1, Table 2, and Table 3 ) is well established in the sense that it covers various phases of a construction project together with various aspects, such as technical, contractual, and people-related. In this regard, it also imposes a reasonable initial clustering. Tables 1,2 and 3 do not include factors that were related to "cost increase" (Adriaanse, 2005), "cost overrun" (Viswanathan et al., 2020), "final certificate and final payments" (Watts \& Scrivener, 1995), "extension of time" (Chan \& Suen, 2005) and "extension of time claims" (Waldron, 2006). Such factors are excluded because the underlying causes are aimed to be captured, rather than cost impacts leading to disputes.

The initial causal map with concepts and links was projected and handed out to the participants. This initial map was revised and enhanced through the reflections of the expert views regarding the issues and aspects. In this sense, experts have shared substantial insight both through cases from their previous experiences as to "how" and "why" disputes occur and through views on the initial and revised map. Cases from previous experience covered a broad range of issues from changes and variations to force majeure, generally confirming the initial map while suggesting the inclusion of new concepts and causal relations. Despite the extensive body of information recorded during the workshop, for convenience, only a few are given here as examples. For example, Expert $\mathrm{C}$ explained a case from a wastewater project implemented through FIDIC forms of contract. In that project, the construction site was in the close vicinity of the stream bed, and part of the project was flooded due to heavy rains. The contractor argued it was a disastrous event and must be considered as a force majeure. The issue manifested as a dispute between the contractor and the employer because the flood did not affect the entire construction site but only a part of it. Moreover, there was no clear definition in the contract as to at which point such an event can be considered as force majeure. Based on this case, Expert $\mathrm{C}$ noted that whenever there is an ambiguity in the contract terms, then room for a claim and possibly for a dispute is created. To reflect this view, a new concept, "Inadequate definition of force majeure", was added to the map under the category of Process-Construction Contract.

Pointing out to differing subsoil conditions, Expert D shared a case from a project in Gaziantep (Turkey) where the employer conducted a soil survey and provided the results as a report within tender documents. However, the contractor encountered a soil type different than what was specified in the soil report provided by the employer, and the issue caused a dispute between the parties. Expert E noted that this is considered under unforeseen ground conditions in FIDIC. To reflect this expert view, the concept "unforeseen ground conditions" was revised as "unforeseen ground conditions / wrong soil class reported by the employer", which was governed under clause 4.12 of FIDIC Yellow Book.

In addition to the specific views, a significant suggestion by the experts added great insight into the study. The suggestion was to include governing FIDIC Yellow Book clauses under each concept where applicable, to enable mapping of the relations between related contract clauses. Hence, governing FIDIC Clauses were added to the concepts (shown in parenthesis) as appropriate. The initial map (concepts and links) was constructed by the researchers as a starting point for discussions, building up on the existing literature.The experts modified the concepts and links based on their practical experience, so that the map could reflect the emergence of disputes for $\mathrm{DB}$ projects under FIDIC contracts. In summary, the following changes were made on the initial map as per expert views;

- New concepts were added;

- Concepts without a notable effect were removed;

- Overlapping concepts were merged to form new inclusive concepts to avoid duplicates and confusion;

- Vague concepts were rephrased;

- New links were introduced between the concepts; and

- Non-influential or negligible links were removed.

As opposed to extensive change-requiring expert views on the initial round, views on the revised map were minimal, requiring only minor revisions in the second round. This shows that the opinions of the experts on the occurrence of construction disputes were successfully reflected on the revised map, confirming the accuracy of the final map. Once changes related to the second round of expert views were made, the final causal map (Figure 2) was achieved.

\subsection{Analysis of the causal map}

According to the result of the domain analysis carried out to identify the top 5 concepts in terms of link density, the busiest concept is "changes and variations" with 13 links. Having 11 links, the second most busy concept is "delays by contractor". Next comes the "errors in concept design and planning" and "prevention of progress by employer" both having 10 links. The last busiest concept 


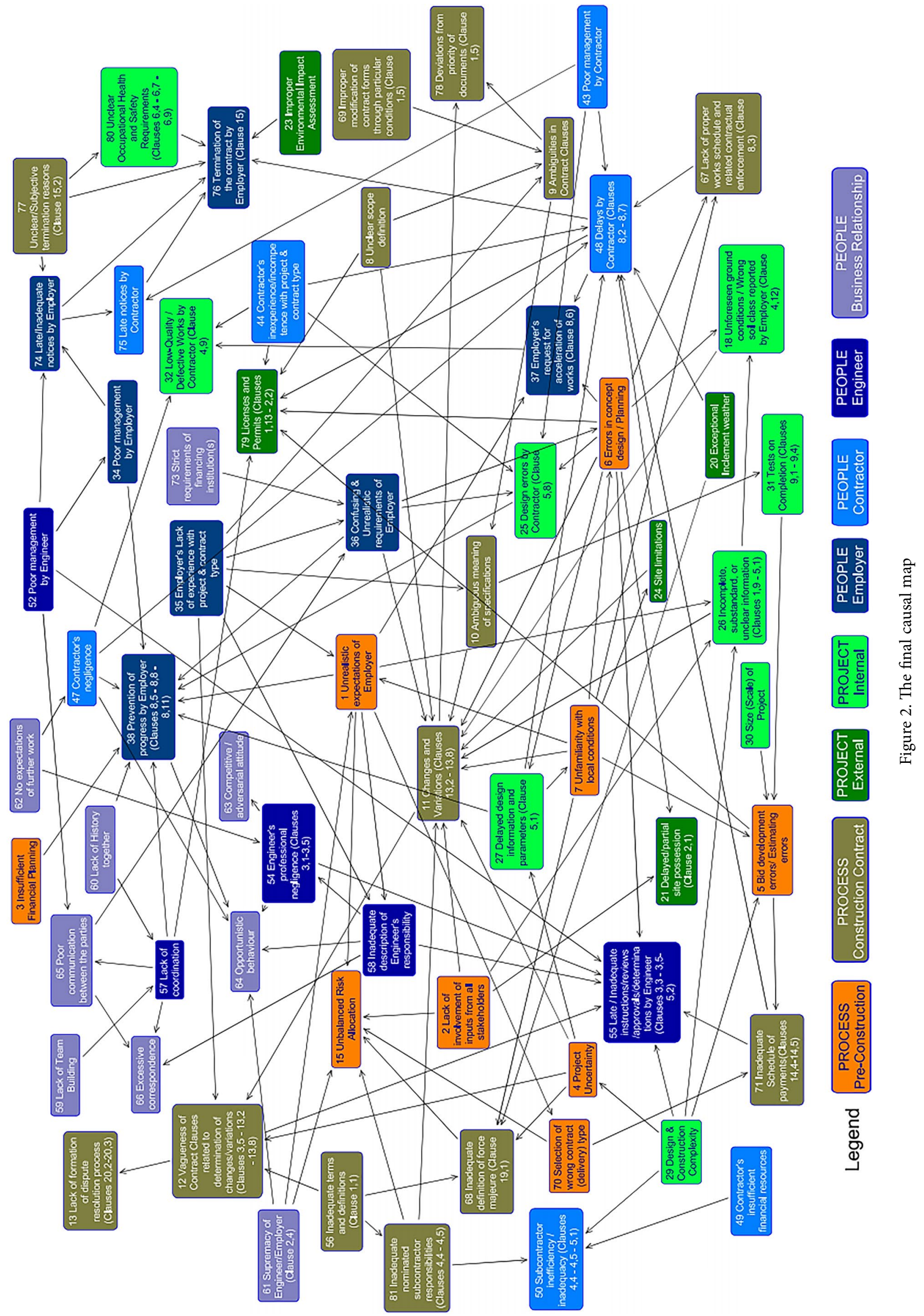


is "unrealistic expectations of employer". This first stage of analysis provided a quick overview of the issue, pointing out possibly the most significant causes of disputes having the highest number of relations. However, since domain analysis counts only the links immediately around the concept ignoring its further effect on other concepts, it reflects a narrow perspective requiring additional analysis for more reliable insights.

The result of the centrality analysis shows that "changes and variations" is still the highest-ranking concept with a centrality score of 31 from 56 total concepts it is linked to. This score can be considered as reinforcing the significant impact of changes and variations on disputes. "Errors in concept design and planning" is the second most influential concept as per centrality analysis together with "unrealistic expectations of employer" both having a score of 30 from 59 concepts. These are followed by "delays by contractor" and "prevention of progress by the employer", with centrality scores of 29 from 58 concepts and 29 from 55 concepts, respectively. The comparison of this list with the result of domain analysis shows both lists include the same concepts with a slightly different ranking.

No loops were identified in the analysis. However, the interactions revealed various causal link paths. Figure 3 depicts the resulting map for "changes and variations", revealing 11 different paths leading to this concept with a total of 14 concepts. Initial inferences of the map are the high level of interaction among concepts and 11 inward links compared to only one going outward, illustrating "changes and variations" resulting from other causal patterns. In addition to direct impacts, "changes and variations" may also be caused by a combination of several concepts where some concepts can contribute in both ways. Another pivotal implication of this map is that the only outgoing link from "changes and variations" is leading to concept 12 . This finding indicates that "changes and variations" manifest as a dispute with the presence of vague contract clauses regarding the determination of these matters.

Both analyses suggested "changes and variations" as the most significant cause of disputes, followed by "errors in concept design and planning", confirming the consistency in the insights reflected in the map. A closer look into the results of domain and centrality analyses reveals that the differences in total link counts and centrality scores are minimal. Such a minimal difference indicates a somewhat uniform/similar impact instead of pointing out only one major cause.

Figure 4 shows the map for the second most significant cause of disputes, "errors in concept design and planning". In this map, 9 outgoing and only 2 incoming links are observed. The high number of outgoing links, when compared to incoming ones, indicates that "errors in concept design and planning" play a rather radical role in the occurrence of construction disputes. At the same time, the two incoming links point out possible issues underlying such errors, which are employer's confusing or unrealistic requirements and lack of familiarity with local conditions.

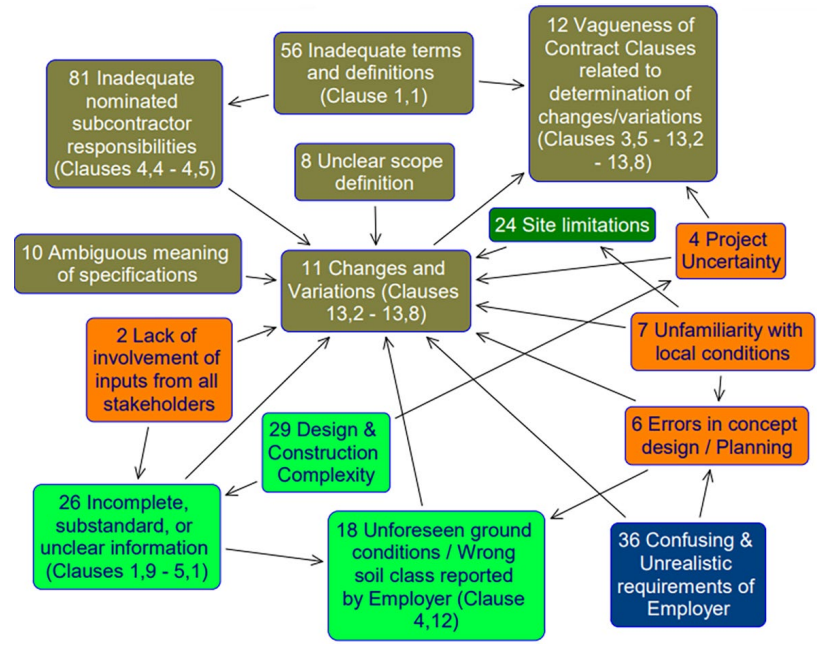

Figure 3. Causal map for changes and variations

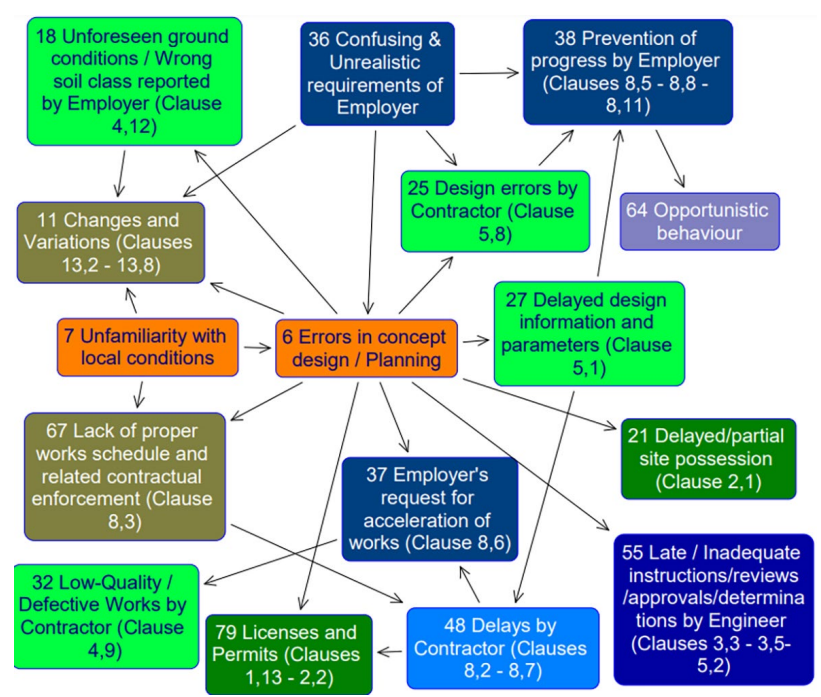

Figure 4. Causal map for errors in concept design and planning

Per initial clustering, the top five causes involve concepts from pre-construction (concepts 1 and 6), construction contract (concept 11), and people (concepts 38 and 48). This reflection indicates that the endeavours prior to construction play a significant role just as the construction contract itself. It also shows the importance of the human factor in the occurrence of disputes, specifically pointing out delays. From another perspective, the factors in the pre-construction category are mainly the root causes of many causal paths. However, as expected, their impacts are mediated by the characteristics of the project (e.g., size, complexity), the employer (e.g., supremacy, lack of experience, unrealistic expectations), and the contract (e.g., inadequate subcontractor responsibility, inadequate definition of force majeure).

As another important finding in terms of clustering, no concepts from the project cluster were ranked among the top five concepts. Mainly comprised of technical and physical issues, the absence of this group can perhaps be explained by virtue of other clusters. Paying adequate at- 
tention to pre-construction studies, contract clauses, and people factor renders such technical issues more manageable.

Further examination of the concepts causing to and stemming from the two most influential causes yielded highly dense links around the subject concepts. While the "changes and variations" appeared as a result of a series of other causes, "errors in concept design and planning" emerged as a far-reaching cause. The most important inference of this examination is that although being the two most significant causes, a change or a variation should concur with the vagueness of governing contract terms to give rise to a dispute. Similarly, the map suggests that concept design and planning errors may result from unfamiliarity of local conditions and employer's confusing/ unrealistic requirements.

\section{Discussion of findings}

When compared with the literature, significant similarities are observed. For instance, three out of six most frequently cited causes according to Tables 1, 2, and 3 are also the three busy concepts in this study ("variations/ change orders", "delays in payment by employer", and "delays by contractor"). The other frequent three concepts ("ambiguities in contract documents", "delayed/partial site possession", and "poor communication between parties") also had moderate to high link densities. Moreover, El-Sayegh et al. (2020) ranked the top three disputes as variations initiated by the owner, obtaining permits/approval from the municipality/different government authority, and material change and approval during the construction phase. Our results are parallel in terms of changes and variations, and prevention of progress by employer being two of the main factors. Though permits/approvals were considered as a part of another concept in the initial map, experts' iterations resulted in a new concept named "licenses and permits". While it is still a high-density head concept, due to the nature of FIDIC conditions and DB contracts, it has not been revealed as one of the top factors. Majority of the concepts that were removed from the map (e.g., inferences with utility lines, the difference in construction technique, and engineer's experience with project type) and merged with other concepts (e.g., non-practical obligations) were some of the least cited factors presented in Tables 1, 2, and 3. Such findings coincide with the literature, verifying reflectivity.

In addition to the similarity of findings to the existing literature, some differences were observed. For instance, Kumaraswamy (1997) categorized the dispute causes into two, as (i) root causes, such as unrealistic targets, unfair risk allocation, adverse culture, unrealistic information expectations, and inappropriate contract types, and (ii) proximate causes, such as contract administration, delayed response, erroneous design information, and unsuitable contractor selection (Viswanathan et al., 2020). The causal map developed in this study revealed alternative causation relations. All of the root causes identified by Kumaraswamy (1997) have more than one causal path leading to these concepts in this study. For instance, selecting the wrong contract type and unclear risk allocation are influenced by unrealistic expectations of the employer. Moreover, employer's lack of experience, poor communication, and strict requirements lead to unrealistic target and information expectations. Furthermore, unsuitable contractor selection and error in design documents are identified more as root causes than proximate causes. Moreover, Viswanathan et al. (2020) looked into the construction phase of projects and categorized the causes of disputes based on their driving and dependence characteristics as autonomous, dependent, independent, and linkage. While the dependent causes show similarities (e.g., changes and variations, delay by contractor, prevention of progress by employer), most of the factors considered independent in Viswanathan et al. (2020) are found as dependent in this study. For instance, opportunistic behaviour, poor communication, and vagueness of contract clauses have strong dependence and weak driving power (more incoming arrows than outgoing arrows).

Although Tables 1, 2 and 3 provided a reliable basis to develop dispute emergence patterns, the specific focus on FIDIC contracts and DB projects revealed alternative concepts and causal patterns. The final map captures new concepts, such as "unclear/ subjective termination reasons" (clause 15.2), "inadequate schedule of payments" (clauses 14.4-14.5), "inadequate definition of force majeure" (clause 19.1) and "inadequate terms and definitions" (Clause 1.1). These contract specific concepts with moderate link densities signify their role in the emergence of disputes. Some factors did not attract attention in the literature but emerged as significant in this study, such as "unfamiliarity with local conditions" and "no expectations of further work". These concepts indeed have a mediating role in the emergence of disputes. According to the causal map, "no expectations of further work" leads to contractor's and engineer's negligence, followed by further paths towards opportunistic behavior, low quality works, and delays.

Moreover, two of the least frequently cited concepts in the literature, "design errors by contractor" and "design and construction complexity", emerged as significant concepts with moderate link densities due to the scope of DB projects. In fact, "design and construction complexity", is one of the root causes affecting both the pre-construction (uncertainty, bid development errors), and construction phase (incomplete information, late approvals, subcontractor inefficiency).

Addressing the weakness identified by Love et al. (2010) regarding the lack of contextualization of dispute causes, this study mapped related FIDIC conditions to dispute causes and identified dispute emergence patterns. The final picture of dispute causes reflects the causes that are relevant with respect to responsibilities and requirements governed within FIDIC Yellow Book. It has to be noted that the final causal map and analysis results depend 
on the opinions of 5 experts experienced in the Turkish construction industry. Various studies in the literature discuss the impact of business culture on the occurrence of disputes and selection of different dispute resolution methods, such as Tsai and Chi (2009) about the Taiwan construction industry and Iwamatsu et al. (2008) about the Japanese construction industry. Rooke et al. (2003) propose a taxonomy on claim attitudes and discuss the impacts of culture on dispute occurrence and claims. Thus, the causal map regarding the FIDIC Yellow Book might have been affected by the business culture in the Turkish construction industry as well as the personal judgments of the experts, and can not be generalized. The aim of this study is not to propose a generic causal map applicable under different contexts. Rather, it is to demonstrate how causal mapping can be utilized to explore causes of disputes and analyze interactions to avoid possible disputes within a specific context, which is projects contracted by FIDIC Yellow Book. The causal mapping approach in this study demonstrates that expert opinion can be used to construct causal maps and explore the emergence of disputes in specific types of projects. Experts who collaborated in this study agreed that causal maps (that also include contract conditions) present an effective visual aid to understand dispute emergence patterns and develop strategies to avoid disputes in projects.

\section{Conclusions}

This study uniquely proposes causal mapping as an effective approach to enable understanding of how construction disputes occur and demonstrates its utilization in practice for DB projects contracted through FIDIC Yellow Book. Within this scope, analysis of the final causal map reached as per expert views reveals that certain factors such as "changes and variations", and "errors in concept design and planning" are prominent. However, either they are triggered by series of factors (e.g., unclear scope definition, site limitations, ambiguous meaning of specifications), or they give rise to other causes (e.g., delayed design information and parameters, delayed/partial site possession, unforeseen ground conditions) to eventually form a dispute. In this respect, this study suggests that a comprehensive approach should be undertaken for a complete and practical understanding of construction disputes. Indeed, it is essential to perceive the underlying causes as multifaceted parts of a relatively complex causal network, rather than focusing solely on individual issues. Within such a framework, tracing these causal paths in forward and backward direction to identify further outcomes and the underlying causes (triggers) can provide significant insight towards dispute avoidance. From a practical point of view, based on such an investigation on a causal map for a particular case, one can determine where response efforts should be directed.

Pursuant to the holistic view adopted, the map model covers various phases of a construction project and takes into account the various type of factors, such as: technical (project), contractual, people, and business relationships. Assessment of the analysis results with respect to this initial clustering allows the comprehension of disputes from a broader perspective. When considered from this point of view, the study highlights the particular importance of pre-construction studies in addition to the contract terms. Similarly, the absence of technical and physical factors among the top five concepts suggests that either adequate pre-construction studies, or proper contract terms, or the efficient role of people factor may prevent such issues manifest as a dispute.

It should be noted that the findings might have been affected by the small sample size of experts and business culture within the Turkish construction business. Albeit providing meaningful insights, these findings can not be generalized. Rather, the intended outcome is to layout context-specific understandings of experts on the emergence of disputes. The causal map produced for FIDIC Yellow Book used for DB projects should be considered as a demonstrative study about how causal maps can be used to trace and understand the emergence of disputes under different contexts. FIDIC has many similarities and differences with other international contracts in terms of format and content (Heaphy, 2013; Besaiso et al., 2018). Such differences and variations within FIDIC books and with other international contracts necessitate the development of causal maps of dispute emergence for other contracts as future research directions.

Causal mapping is a powerful qualitative research technique that is widely used for the analysis and investigation of complex phenomena. The study contributes to the literature in the project management domain by demonstrating the application of the technique to construction disputes and showing the capability to uncover valuable insight that would not have been possible with other approaches. Moreover, combining two sources of data elicitation (documents and workshop), the study puts forward a profound procedure that significantly reduces the time required for map creation, which would help wider use of the technique.

Analysis and interpretation of the map model yield extensive information that can readily be applied to actual projects and cases. In this sense, serving as an effective tool for dispute avoidance, risk management, and decision making, the study is believed to be beneficial for the professionals, especially responsible for project and contract management. The identified causal patterns and links can be represented in a dispute prediction tool, and the approach can be utilized in an ex-post context to explore and defend claims/disputes.

Due to the adopted methodology and the nature of the issue at hand, the study also has some limitations, such as subjectivity in causal mapping could yield different results with different experts. Owing to the high number of concepts and their relations, constructing a map from scratch requires quite significant time. For this reason, the initial 
map, built based on literature (instead of expert views) to minimize the expert time, may be considered to have induced biases on expert views. Also, as the study considers only disputes in projects contracted through FIDIC Yellow Book, the implications of the study are somewhat limited to this form of contract. However, findings shared in this article can provide a comparative contextual reference for other contract types.

There are also potential research areas that can provide benefits to theory and practice. Although this study considers construction disputes within a broad context, focusing on certain types of disputes (e.g., time extension disputes, payment disputes, quality disputes) may yield specific results and insight pertaining to the occurrence of such disputes. The final map can be applied to one or more projects using dispute documents to verify and tailor the model to specific characteristics of the projects. A causal map of a particular dispute type can be used as a post-mortem analysis tool for delay and disruption claims/disputes by combining the technique with suitable quantitative methods such as system dynamics. Weighted cognitive maps can be developed to assign relative strengths of the links and identify the most critical paths. The technique can also be applied to explore only certain factors contributing to disputes in order to identify possible scenarios and anticipate associated results in advance. A longitudinal approach enabling the map model to evolve would be highly beneficial to explore the emergence of disputes throughout various phases of project implementation.

\section{Acknowledgements}

The authors express sincere thanks to Mr. Ender Senkaya, Mr. Ali Bedii Candas, and Dr. Osman Acar for sharing their knowledge with the research team.

\section{Funding}

This research received no external funding.

\section{Author contributions}

The authors I.D. and M.T.B. conceived the idea and designed the study. Author C.T. was responsible for data collection and analysis. All authors (C.T., G.A., I.D., and M.T.B.) were responsible for verification of the methods and data interpretation. Authors C.T. and I.D. wrote the initial draft of the article, authors G.A. and M.T.B. critically revised the manuscript.

\section{Disclosure statement}

Authors confirm that they do not have any competing financial, professional, or personal interests from other parties.

\section{References}

Acharya, N. K., Dai Lee, Y., \& Im, H. M. (2006). Conflicting factors in construction projects: Korean perspective. Engineering, Construction and Architectural Management, 13(6), 543-566. https://doi.org/10.1108/09699980610712364

Ackermann, F., \& Alexander, J. (2016). Researching complex projects: Using causal mapping to take a systems perspective. International Journal of Project Management, 34(6), 891-901. https://doi.org/10.1016/j.ijproman.2016.04.001

Ackermann, F., \& Eden, C. (2010). Strategic options development and analysis. Springer London.

https://doi.org/10.1007/978-1-84882-809-4_4

Ackermann, F., \& Eden, C. (2011). Making strategy: Mapping out strategic success. Sage.

Ackermann, F., Eden, C., \& Williams, T. (1997). Modeling for litigation: Mixing qualitative and quantitative approaches. Interfaces, 27(2), 48-65. https://doi.org/10.1287/inte.27.2.48

Ackermann, F., Howick, S., Quigley, J., Walls, L., \& Houghton, T. (2014). Systemic risk elicitation: Using causal maps to engage stakeholders and build a comprehensive view of risks. European Journal of Operational Research, 238(1), 290-299. https://doi.org/10.1016/j.ejor.2014.03.035

Adriaanse, J. (2005). Construction contract law: The essentials. Palgrave-MacMillan.

Arif, F., \& Saeed, F. (2021). Role of construction project documentation for effective arbitration process. Journal of Legal Affairs and Dispute Resolution in Engineering and Construction, 13(2), 04521006. https://doi.org/10.1061/(ASCE)LA.1943-4170.0000466

Ashworth, A. (2005). Contractual procedures in the construction industry. Pearson Longman.

Axelrod, R. (2015). Structure of decision: The cognitive maps of political elites. Princeton University Press. https://doi.org/10.1515/9781400871957

Banxia. (2017). Decision explorer: User's guide version 3.5.0. Banxia Software Limited, Kendal, UK. https://banxia.com/pdf/de/DEGuide.pdf

Besaiso, H., Fenn, P., Emsley, M., \& Wright, D. (2018). A comparison of the suitability of FIDIC and NEC conditions of contract in Palestine. Engineering, Construction and Architectural Management, 25(2), 241-256.

https://doi.org/10.1108/ECAM-10-2016-0235

Bristow, D., \& Vasilopoulos, R. (1995). The new ccdc2: facilitating dispute resolution of construction projects. Construction Law Journal, 11(2), 95-117.

Bryson, J. M., Ackermann, F., \& Eden, C. (2014). Visual strategy: Strategy mapping for public and nonprofit organizations. John Wiley \& Sons.

Bryson, J. M., Ackermann, F., Eden, C., \& Finn, C. B. (2004). Visible thinking: Unlocking causal mapping for practical business results. John Wiley \& Sons.

Chan, E. H., \& Suen, H. C. (2005). Dispute resolution management for international construction projects in China. Management Decision, 43(4), 589-602.

https://doi.org/10.1108/00251740510593576

Cheung, S. O. (2014). Construction dispute research: Conceptualisation, avoidance and resolution. Springer.

Cheung, S. O., \& Yiu, T. W. (2006). Are construction disputes inevitable?. IEEE Transactions on Engineering Management, 53(3), 456-470. https://doi.org/10.1109/TEM.2006.877445 
Cheung, S. O., \& Pang, K. H. Y. (2013). Anatomy of construction disputes. Journal of Construction Engineering and Management, 139(1), 15-23.

https://doi.org/10.1061/(ASCE)CO.1943-7862.0000532

Cheung S. O., \& Pang, K. H.Y. (2014). Conceptualising construction disputes. In S. Cheung (Ed.), Construction dispute research. Springer.

https://doi.org/10.1007/978-3-319-04429-3_2

Cossette, P., \& Audet, M. (1992). Mapping of an idiosyncratic schema. Journal of Management Studies, 29(3), 325-347. https://doi.org/10.1111/j.1467-6486.1992.tb00668.x

Creed, S. E., \& Joon, H. P. (2009). Risk index model for minimizing environmental disputes in construction. Journal of Construction Engineering and Management, 135(1), 34-41. https://doi.org/10.1061/(ASCE)0733-9364(2009)135:1(34)

Diekmann, J. E., \& Girard, M. J. (1995). Are contract disputes predictable?. Journal of Construction Engineering and Management, 121(4), 355-363. https://doi.org/10.1061/(ASCE)0733-9364(1995)121:4(355)

Eden, C. (1992). On the nature of cognitive maps. Journal of Management Studies, 29(3), 261-265.

https://doi.org/10.1111/j.1467-6486.1992.tb00664.x

Eden, C., \& Ackermann, F. (2004). Cognitive mapping expert views for policy analysis in the public sector. European Journal of Operational Research, 152(3), 615-630.

https://doi.org/10.1016/S0377-2217(03)00061-4

Eden, C., Spender, J.-C., \& Spender, J. (1998). Managerial and organizational cognition: Theory, methods and research. Sage.

Edkins, A. J., Kurul, E., Maytorena-Sanchez, E., \& Rintala, K. (2007). The application of cognitive mapping methodologies in project management research. International Journal of Project Management, 25(8), 762-772. https://doi.org/10.1016/j.ijproman.2007.04.003

El-Sayegh, S., Ahmad, I., Aljanabi, M., Herzallah, R., Metry, S., \& El-Ashwal, O. (2020). Construction disputes in the UAE: Causes and resolution methods. Buildings, 10(10), 171. https://doi.org/10.3390/buildings10100171

Fenn, P., Lowe, D., \& Speck, C. (1997). Conflict and dispute in construction. Construction Management and Economics, 15(6), 513-518. https://doi.org/10.1080/014461997372719

Federation Internationale des Ingenieurs-Conseils. (1999). FIDIC Conditions of contract for plant and design build (1st ed.). Geneva, Switzerland.

Fisher, J. (1988). Prevention is better than cure, or how to avoid costly mistakes in hong kong construction contracts. The International Construction Law Review, (July/Oct), 342-348.

Georgiou, I. (2010). Cognitive mapping and Strategic Options Development and Analysis (SODA). Wiley Encyclopedia of Operations Research and Management Science.

https://doi.org/10.1002/9780470400531.eorms0974

Goodier, C. I., \& Soetanto, R. (2013). Building future scenarios using cognitive mapping. Journal of Maps, 9(2), 203-217. https://doi.org/10.1080/17445647.2013.770997

Heaphy, I. (2013). NEC versus FIDIC. Proceedings of the Institution of Civil Engineers-Management Procurement and Law, 166(1), 21-30. https://doi.org/10.1680/mpal.11.00006

Hewitt, R. (1991). Winning contract disputes: Strategic planning for major litigation. Ernst \& Young.

Hodgkinson, G. P., \& Clarkson, G. P. (2005). What have we learned from almost 30 years of research on causal mapping? Methodological lessons and choices for the information systems and information technology communities. In G. P. Hodgkinson (Ed.), Causal mapping for research in information technology (pp. 46-80). IGI Global.

https://doi.org/10.4018/978-1-59140-396-8.ch003
Huff, A. S. (1990). Mapping strategic thought. John Wiley \& Sons. Ilter, D. (2012). Identification of the relations between dispute factors and dispute categories in construction projects. International Journal of Law in the Built Environment, 4(1), 45-59. https://doi.org/10.1108/17561451211211732

Iwamatsu, J., Akiyama, T., \& Endo, K. (2008). Construction claims and disputes and the business culture of construction in Japan. Journal of Professional Issues in Engineering Education and Practice, 134(1), 119-127. https://doi.org/10.1061/(ASCE)1052-3928(2008)134:1(119)

Jaffar, N., Tharim, A. A., \& Shuib, M. N. (2011). Factors of conflict in construction industry: a literature review. Procedia Engineering, 20, 193-202.

https://doi.org/10.1016/j.proeng.2011.11.156

Keil, J. H. (1999). Hybrid ADR in the construction industry. Dispute Resolution Journal, 54(3), 14.

Kelly, G. A. (1955). The psychology of personal constructs. Volume 1: A theory of personality. Routledge.

Kumaraswamy, M. (1997). Common categories and causes of construction claims. Construction Law Journal, 13(1), 21-34.

Love, P., Davis, P., Ellis, J., \& Cheung, S. O. (2010). Dispute causation: identification of pathogenic influences in construction. Engineering, Construction and Architectural Management, 17(4), 404-423. https://doi.org/10.1108/09699981011056592

Love, P. E., Davis, P. R., Cheung, S. O., \& Irani, Z. (2011). Causal discovery and inference of project disputes. IEEE Transactions on Engineering Management, 58(3), 400-411. https://doi.org/10.1109/TEM.2010.2048907

Michel, H. L. (1998). Feature the next 25 years: The future of the construction industry. Journal of Management in Engineering, 14(5), 26-31.

https://doi.org/10.1061/(ASCE)0742-597X(1998)14:5(26)

Mitkus, S., \& Mitkus, T. (2014). Causes of conflicts in a construction industry: A communicational approach. Procedia-Social and Behavioral Sciences, 110, 777-786.

https://doi.org/10.1016/j.sbspro.2013.12.922

Mitropoulos, P., \& Howell, G. (2001). Model for understanding, preventing and resolving project disputes. Journal of Construction Engineering and Management, 127(3), 223-231. https://doi.org/10.1061/(ASCE)0733-9364(2001)127:3(223)

Molenaar, K., Washington, S., \& Diekmann, J. (2000). Structural equation model of construction contract dispute potential. Journal of Construction Engineering and Management, 126(4), 268-277.

https://doi.org/10.1061/(ASCE)0733-9364(2000)126:4(268)

Naji, K. K., Mansour, M. M., \& Gunduz, M. (2020). Methods for modeling and evaluating construction disputes: A critical review. IEEE Access, 8, 45641-45652.

https://doi.org/10.1109/ACCESS.2020.2976109

Narayanan, V., \& Armstrong, D. (2005). Causal mapping for research in information technology. IGI Global. https://doi.org/10.4018/978-1-59140-396-8

Parchami Jalal, M., Noorzai, E., \& Yavari Roushan, T. (2019). Root cause analysis of the most frequent claims in the building industry through the $\mathrm{SCoP}_{3} \mathrm{E}$ Ishikawa diagram. Journal of Legal Affairs and Dispute Resolution in Engineering and Construction, 11(2), UNSP 04519004.

https://doi.org/10.1061/(ASCE)LA.1943-4170.0000289

Rhys Jones, S. (1994). How constructive is construction law?. Construction Law Journal, 10, 28-28.

Rooke, J., Seymour, D., \& Fellows, R. (2003). The claims culture: a taxonomy of attitudes in the industry. Construction Management \& Economics, 21(2), 167-174. https://doi.org/10.1080/0144619032000079707 
Sabri, O. K., Lædre, O., \& Bruland, A. (2019). Why conflicts occur in roads and tunnels projects in Norway. Journal of Civil Engineering and Management, 25(3), 252-264. https://doi.org/10.3846/jcem.2019.8566

Santos, L. D., Schlindwein, S. L., Fantini, A. C., Belderrain, M. C. N., Montibeller, G., \& Franco, L. A. (2019). Structuring contrasting forest stakeholders' views with the Strategic Options Development and Analysis (SODA) approach. International Forestry Review, 21(4), 501-515. https://doi.org/10.1505/146554819827906834

Semple, C., Hartman, F. T., \& Jergeas, G. (1994). Construction claims and disputes: Causes and cost/time overruns. Journal of Construction Engineering and Management, 120(4), 785-795. https://doi.org/10.1061/(ASCE)0733-9364(1994)120:4(785)

Sheridan, P. (2003). Claims and disputes in construction. Construction Law Journal, 12(1), 3-13.

Spittler, J. R., \& Jentzen, G. H. (1992). Dispute resolution: Managing construction conflict with step negotiations. AACE International Transactions, 1(1), 9-19.

Sykes, J. (1996). Claims and disputes in construction. Construction Law Journal, 12(1), 3-13.

Tolman, E. C. (1948). Cognitive maps in rats and men. Psychological Review, 55(4), 189-208.

https://doi.org/10.1037/h0061626

Tsai, J. S., \& Chi, C. S. (2009). Influences of Chinese cultural orientations and conflict management styles on construction dispute resolving strategies. Journal of Construction Engineering and Management, 135(10), 955-964. https://doi.org/10.1061/(ASCE)0733-9364(2009)135:10(955)

Viswanathan, S. K., Panwar, A., Kar, S., Lavingiya, R., \& Jha, K. N. (2020). Causal modeling of disputes in construction projects. Journal of Legal Affairs and Dispute Resolution in Engineering and Construction, 12(4), 04520035.

https://doi.org/10.1061/(ASCE)LA.1943-4170.0000432

Vygotsky, L. S. (1980). Mind in society: The development of higher psychological processes. Harvard University Press. https://doi.org/10.2307/j.ctvjf9vz4

Waldron, B. D. (2006). Scope for improvement: A survey of pressure points in Australian construction and infrastructure projects (Report prepared for the Australian Constructors Association by Blake Dawson Waldron Lawyers). Sydney, Australia.

Watts, V., \& Scrivener, J. (1995). Building disputes settled by litigation: comparison of Australian and UK practices. Building Research and Information, 23(1), 31-38. https://doi.org/10.1080/09613219508727421

Yates, D. (1999). Conflict and disputes in the development process: A transaction cost economics perspective (Working Paper).

Yiu, K. T., \& Cheung, S. O. (2006). A catastrophe model of construction conflict behavior. Building and Environment, 41(4), 438-447. https://doi.org/10.1016/j.buildenv.2005.01.007 